\title{
Congruence between morphology-based species and Barcode Index Numbers (BINs) in Neotropical Eumaeini (Lycaenidae)
}

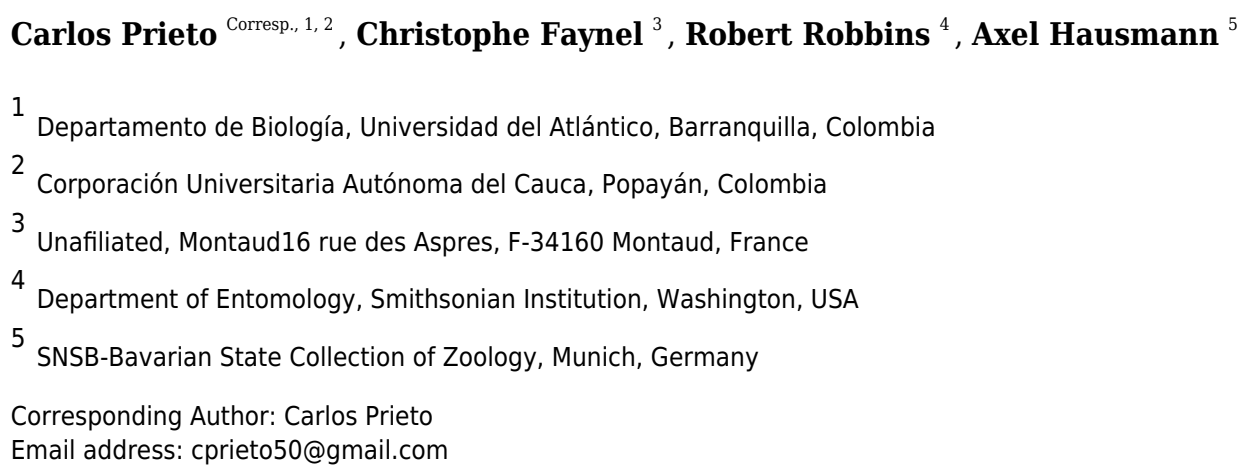

Background: With about 1000 species in the Neotropics, the Eumaeini butterflies (Theclinae) are one of the most diverse tribes among the Lycaenidae. Correct morphologybased identifications are challenging in many genera due to relatively little interspecific differences in wing patterns. Geographic infraspecific variation is sometimes more substantial than variation between species. In this paper we present a large DNA barcode dataset of South American Lycaenidae. We analyze how well DNA barcode BINs match morphologically delimited species. Methods: We compare morphology-based species identifications with the clustering of molecular operational taxonomic units (MOTUs) delimitated by the RESL algorithm in BOLD, which assigns Barcode Index Numbers (BINs). We examine intra- and interspecific divergences for genera represented by at least four morphospecies. We discuss the existence of local barcode gaps in a genus by genus analysis. We also note differences in the percentage of species with barcode gaps in groups of lowland and high mountain genera. Results: We identified 2213 specimens and obtained 1839 sequences of 512 species in 90 genera. Overall, the mean intraspecific divergence value of $\mathrm{CO} 1$ sequences was $1.20 \%$, while the mean interspecific divergence between nearest congeneric neighbors was $4.89 \%$, demonstrating the presence of a barcode gap. However, the gap seemed to disappear from the entire set when comparing the maximum intraspecific distance $(8.40 \%)$ with the minimum interspecific distance $(0.40 \%)$. Clear barcode gaps are present in many genera but absent in others. From the set of specimens that yielded COI fragment lengths of at least $650 \mathrm{bp}, 75 \%$ of the a priori morphology-based identifications were unambiguously assigned to a single Barcode Index Number (BIN). However, after a taxonomic a posteriori review, the percentage of matched identifications rose to $85 \%$. BIN splitting was observed for $17 \%$ of the species and BIN 
sharing for $9 \%$. We found that genera that contain primarily lowland species show higher percentages of local barcode gaps and congruence between BINs and morphology than genera that contain exclusively high montane species. The divergence values to the nearest neighbors were significantly lower in high Andean species while the intra-specific divergence values were significantly lower in the lowland species. These results raise questions regarding the causes of observed low inter and high intraspecific genetic variation. We discuss incomplete lineage sorting and hybridization as most likely causes of this phenomenon, as the montane species concerned are relatively young and hybridization is probable. The release of our data set represents an essential baseline for a reference library for biological assessment studies of butterflies in mega diverse countries using modern high-throughput technologies an highlights the necessity of taxonomic revisions for various genera combining both molecular and morphological data. 
1 Congruence between morphology-based species and Barcode Index Numbers (BINs) in

2 Neotropical Eumaeini (Lycaenidae)

3

4 Carlos Prieto $^{1,2}$, Christophe Faynel ${ }^{3}$, Robert K. Robbins ${ }^{4} \&$ Axel Hausmann ${ }^{5}$

5

$6{ }^{1}$ Departamento de Biología, Universidad del Atlántico, Barranquilla, Colombia

$7 \quad 2$ Corporación Universitaria Autónoma del Cauca, Popayán, Colombia.

$8{ }^{3} 16$ rue des Aspres, F-34160 Montaud, France.

$9{ }^{4}$ Department of Entomology, Smithsonian Institution, Washington, USA.

$10{ }^{5}$ SNSB-Bavarian State Collection of Zoology, Munich, Germany.

11

12

Corresponding Author:

13 Carlos Prieto ${ }^{1,2}$

14 Email address: cprieto50@gmail.com

15

\section{Abstract}

Background: With about 1000 species in the Neotropics, the Eumaeini butterflies (Lycaenidae, Theclinae) are one of the most diverse tribes among the Lycaenidae. Correct morphology-based identifications are challenging in many genera due to relatively little interspecific differences in wing patterns. Geographic infraspecific variation is sometimes more substantial than variation between species. In this paper we present a large DNA barcode dataset of South American Lycaenidae. We analyze how well DNA barcode BINs match morphologically delimited species.

Methods: We compare morphology-based species identifications with the clustering of molecular operational taxonomic units (MOTUs) delimitated by the RESL algorithm in BOLD, which assigns Barcode Index Numbers (BINs). We examine intra- and interspecific divergences for genera represented by at least four morphospecies. We discuss the existence of local barcode gaps in a genus by genus analysis. We also note differences in the percentage of species with barcode gaps in groups of lowland and high mountain genera.

Results: We identified 2213 specimens and obtained 1839 sequences of 512 species in 90 genera. Overall, the mean intraspecific divergence value of CO1 sequences was $1.20 \%$, while the mean interspecific divergence between nearest congeneric neighbors was $4.89 \%$, demonstrating the typical presence of a barcode gap. However, the gap seemed to disappear from the entire set when comparing the maximum intraspecific distance $(8.40 \%)$ with the minimum interspecific distance $(0.40 \%)$. Clear barcode gaps are present in many genera but absent in others. From the set of specimens that yielded COI fragment lengths of at least $650 \mathrm{bp}, 75 \%$ of the a priori morphology-based identifications were unambiguously assigned to a single Barcode Index Number (BIN). However after a taxonomic a posteriori review, the percentage of matched identifications rose to $85 \%$. BIN splitting was observed for $17 \%$ of the species and BIN sharing 
42

43

44

45

46

47

48

49

50

51

52

53

54

55

56

57

58

59

60

61

62

63

64

65

66

67

68

69

70

71

72

73

74

75

76

77

78

79

80
41 local barcode gaps and congruence between BINs and morphology than genera that contain
42 exclusively high montane species. The divergence values to the nearest neighbors were significantly lower in high Andean species while the intra-specific divergence values were significantly lower in the lowland species. These results raise questions regarding the causes of observed low inter and high intraspecific genetic variation. We discuss incomplete lineage sorting and hybridization as most likely causes of this phenomenon, as the montane species concerned are phylogenetically young and hybridization is probable. The release of our data set represents an essential baseline for a reference library for biological assessment studies of butterflies in mega diverse countries using modern high-throughput technologies and also highlights the necessity of taxonomic revisions for various genera combining both molecular and morphological data.

\section{Introduction}

The ability to delimit and identify species is the foundation for addressing diversity issues in evolution, ecology, conservation, and biogeography. DNA barcodes potentially offer the opportunity for the rapid determination of species in large faunas, but reference libraries are needed to take advantage of this technique (Wirta et al. 2016; Hajibabaei et al. 2006). As of mid-2020, the Barcode of Life Database global repository (BOLD, http://www.boldsystems.org; Ratnasingham \& Hebert 2007) includes more than 9 million DNA barcode sequences for over 224,000 metazoans (700,000 BINs, including many not yet identified taxa) and 69,000 plant species. There are DNA barcodes from species in every country worldwide, with many supporting national barcoding initiatives. Each specimen in BOLD with a sequence longer than $500 \mathrm{bp}$ is automatically assigned a global unique identifier (BIN, Barcode Index Number) based on the Refined Single Linkage (RESL) algorithm (Ratnasingham \& Hebert 2013). BIN assignments can be updated when new records reveal clear sequence divergence structure. DNA barcodes accurately delimit species in a number of large-scale studies (e.g., birds, Hebert et al. 2004b; Kerr et al. 2007; moths, Hebert et al. 2010; Hausmann et al 2011; Huemer et al. 2014; beetles, Hendrich et al. 2014; bees, Schmidt et al. 2015; dipterans, Morinière et al. 2019). They are often useful for discovering cryptic species, as has been shown with butterflies and flies (Hebert et al. 2004a; Smith et al. 2006; van Velzen et al. 2007; Riedel et al. 2013; Espinoza et al., 2017; Janzen et al. 2017; Dias et al., 2019; Tujuba et al. 2020). In many cases, BINs correspond with traditional taxonomy. However, perfect congruence is rare (e.g., Hawlitschek et al. 2017; Pyrcz et al. 2018). While studies of the genetic diversity within a given species requires sampling from many localities (Bergsten et al. 2012), simple identification often requires only a single reference sequence (Hebert et al. 2003; Hausmann et al. 2013; Hawlitschek et al. 2017).

The utility of barcodes for describing several aspects of biodiversity depends on a strong correspondence between morphologically and genetically delimited entities. Although $>20 \%$ of species pairs exhibit some level of incongruence in analyses at a continental scale (cf. Hausmann et al. 2013), the correlation increases significantly if the analyses are geographically restricted,

Peer] reviewing PDF | (2021:02:57879:2:0:NEW 18 Jun 2021) 
81 such as a single country (Hausmann 2011; Hausmann et al. 2013; Hendrich et al. 2014). For

82

83

84

85

86

87

88

89

90

91

92

93

94

95

96

97

98

99

100

101

102

103

104

105

106

107

108

109

110

111

112

113

114

115

116

117

118

119

120

example, DNA barcodes accurately identified more than $95 \%$ of Argentine butterfly species

(Lavinia et al. 2017). The success rate of DNA barcoding also varies among taxa, as can be seen among lepidopteran groups. Although some apparent differences among taxa may be due to biogeographic factors, DNA barcode species identifications were of more limited usefulness in neotropical Ithomiini butterflies (Elias et al. 2007) and Palearctic Elachistidae moths (Kaila \& Stahls 2006), but were more useful in the lepidopteran families Hesperiidae, Sphingidae, Saturniidae, Geometridae and Erebidae (Hajibabaei et al. 2006; Hausmann et al. 2011; Rougerie et al. 2014; Ortiz et al. 2017).

The primarily neotropical Eumaeini (Lycaenidae, Theclinae) contains more than a thousand species (Robbins 2004) and represents one of the most rapid radiations among the butterflies. Taxonomic difficulties, external similarity, small size, rarity, high species richness, and restricted geographical distributions (at least of high montane species) are the most likely causes of the relatively scarce knowledge of this butterfly tribe. In contrast with other, better known families, lycaenids lack sufficiently illustrated identification keys, monographs, field guides, or checklists covering regions or countries in a comprehensive and updated manner. The use of DNA barcode sequences and BINs in this group has been limited, but congruence between morphology and barcode sequences is variable (Prieto et al. 2011; Faynel et al. 2011, 2012; Prieto et al. 2016; Cong et al. 2016, 2017; Prieto \& Lorenc-Brudecka, 2017; Busby et al. 2017, Prieto et al. 2018; Faynel 2019). In particular, in previous studies it appeared that strictly high Andean genera were more likely, on average, to show incongruence.

Incongruence between morphology and barcodes occurs when more than one BIN is detected in a traditionally recognized species or when a BIN number comprises members of more than one recognized species (Hebert et al. $2004 \mathrm{a}, \mathrm{b}$ ). BIN discordance can be caused by unrecognized cryptic diversity whereas BIN sharing may indicate recently separated lineages that are still undergoing genetic differentiation. In both cases, an evidence-based taxonomic choice must be made, either to describe a new species (BIN split) or to synonymize two names (BIN sharing). These taxonomic decisions can increase the percentage of congruence between DNA and morphology-based analyses.

In this paper we present a large DNA barcode dataset of South American Lycaenidae. We analyze genus by genus how well DNA barcode BINs match morphologically delimited species. The general goal is to quantify the potential usefulness of reference libraries of DNA barcodes for identification and for resolution of taxonomic problems in this group. In previous studies (e.g.; Prieto et al. 2016; Prieto et al. 2018; Faynel 2019) we found that congruence between DNA and morphology varies among genera. We hypothesized that the incidence of congruence among strictly high Andean genera was lower than among lowland genera. A specific goal of this paper is to evaluate whether or not the ability of DNA barcodes to discriminate morphologically delimited species decreases in high elevation lineages.

\section{Materials \& Methods}

PeerJ reviewing PDF | (2021:02:57879:2:0:NEW 18 Jun 2021) 
121 Morphology-based species identifications

122 The basis for identifying the species analyzed in this study is the checklist of Robbins (2004),

123 which includes 1058 species of Eumaeini in 83 genera. The checklist was updated using

124 subsequent publications (e.g. Bálint \& Faynel 2008; Prieto et al. 2008; Duarte \& Robbins 2010;

125 Faynel et al. 2011; Prieto 2011; Faynel et al. 2012; Robbins et al. 2015; Prieto et al. 2016; Prieto

126 \& Vargas 2016; Busby et al. 2017). When necessary, identifications were verified through

127 genitalic examination.

128

129

\section{Sampling and sequencing}

130 Collecting permits in Colombia were obtained from ANLA Agencia Nacional de Licencias

131

132

133

134

135

136

137

138

139

140

141

142

143

144

145

146

147

148

149

150

151

152

153

154

155

156

157

158

159

160

Ambientales (00594 April 26th 2018). Tissue samples were taken from pinned Eumaeini (Theclinae) in the research collections of Carlos Prieto (RCCP) and Christophe Faynel (RCCF). We selected specimens collected in the past 10 years because older material is more likely to have degraded DNA. Samples came from Costa Rica, French Guiana, Colombia, Ecuador, Peru, and Brazil (Figure 1). One to three legs were removed from each sampled specimen. The sample included 2,214 specimens of 541 species identified a priori based on the existing classification. The number of specimens per species ranged from two to 23 . DNA extraction, amplification, and sequencing of the COI barcode region were carried out by the Canadian Centre for DNA Barcoding (CCDB), Ontario, Canada, using standard high throughput protocols (Ivanova et al. 2006; deWaard et al. 2008). PCR amplification with a single pair of standard primers targeted a 658 bp region near the 5' terminus of the mitochondrial cytochrome $\mathrm{c}$ oxidase I (COI) gene that included the standard $648 \mathrm{bp}$ barcode region for the animal kingdom (Hebert et al. 2004a). Complete specimen data including images, voucher deposition, accession numbers, GPS coordinates, sequence and trace files are accessible in the Barcode of Life Data System (BOLD dataset: DS-CPCF Faynel-Prieto Neotropical Theclinae; doi: https://dx.doi.org/10.5883/ DS-CPCF). Distance-based Neighbor joining (NJ), available on the BOLD website, was used to construct DNA barcode gene trees and to quantify sequence divergence. We analyzed the entire dataset and each genus with the $\mathrm{NJ}$ algorithm. In some cases, nearest neighbor genera with few species were combined in a single tree.

\section{Congruence between morphology and BINs}

BOLD currently contains close to 9,000,000 barcodes and over 700,000 BINs generated with the Refined Single Linkage (RESL) algorithm. RESL employs a three phased analysis to reach decisions on the number and circumscription of BINs (= MOTUs) in the sequence data set on BOLD (Ratnasingham \& Hebert 2013). It is much faster than other approaches, such as the generalized mixed Yule-coalescent model (Pons et al. 2006; Fujisawa \& Barraclough 2013), a critical requirement for the analysis of large data sets.

Morphological species were partitioned into three categories following the comparative methodology of Hausmann et al. (2013): (I) those in which there was a perfect match between morphological species and BINs; (II) splits: those were morphological species placed in more

Peer) reviewing PDF | (2021:02:57879:2:0:NEW 18 Jun 2021) 
161 than one BIN and (III) merges: those where different species shared the same BIN assignment or

162

163

164

165

166

167

168

169

170

171

172

173

174

175

176

177

178

179

180

181

182

183

184

185

186

187

188

189

190

191

192

193

194

195

196

197

198

199

200

mixtures where some individuals of a species shared a BIN with another morphological species.

We re-examined each sample in the latter two cases by checking both the morphological identification and the alignment and trace files.

\section{Barcode gaps}

We analyzed barcode gaps to evaluate the hypothesis that incongruence between morphological species and BINs increase in high Andean lycaenid genera (e.g. Prieto et al. 2018; Faynel 2019). The "barcode gap" is a comparison of intraspecific versus interspecific divergence among barcode sequences. A barcode gap exists if the intraspecific divergence (of a particular species) is smaller than its lowest interspecific divergence. For example, a small intraspecific divergence combined with a large interspecific divergence is a large gap. We compared these divergences in the entire dataset and in groups of genera partitioned by the elevational distribution of its species. The criterion for assigning elevational groups was that at least $90 \%$ of the species in a genus occur in 1) high mountain habitats $(+2200 \mathrm{~m}), 2)$ middle mountain habitats $(1220 \mathrm{~m}-2200 \mathrm{~m}), 3)$ lowland habitats $(0 \mathrm{~m}-1200 \mathrm{~m}), 4)$ middle mountain + high mountain and, 5) or lowland + middle mountain.

As a quick visualization of barcode gaps, we made scatterplots showing maximum intraspecific variation plotted against the minimum distance to the nearest non-conspecific individual. A 1:1 relationship is the point at which the difference between the two is zero (Collins \& Cruickshank 2013). To determine sampling size bias, we also made scatterplots with the number of individuals in each species plotted against their maximum intraspecific variation. These analyses were performed for genera with at least two species and five sequences and for the groups of genera according to their elevational category. To evaluate if the divergence patterns for intraspecific variation and distances to nearest neighbor differ between the sets of species occurring in high mountain and lowland habitats, a Shapiro-Wilk normality test (Shapiro \& Wilk, 1965), and a Kruskall-Wallis test were performed. The analyzes were carried out in R software.

\section{Results}

DNA barcode sequences at least 500 base pairs (bp) in length were successfully recovered from 1839 specimens. These sequences were assigned to $556 \mathrm{BIN}$ numbers that belong to 512 morphology-based species in 90 genera. From the congruence analysis (1597 sequences, 558 BINs, 398 species, 52 genera) mean intraspecific variation ranged from a low of $0.1 \%$ in Paraspiculatus to a maximum value of $3.85 \%$ in Cyanophrys. Mean distances to nearest neighbor species ranged from $2.3 \%$ in Contrafacia to $10.4 \%$ in Aubergina. Altogether, 299 (75\%) morphology-based species perfectly matched a unique BIN, while 36 species $(9 \%)$ shared a BIN with up to six species, and 60 species (17.33\%) were placed in two or more BINs. After reevaluating the morphology-based species based on the molecular results, congruence between morphology and BINs rose to $85 \%$. However, BIN sharing and BIN splitting were particularly

PeerJ reviewing PDF | (2021:02:57879:2:0:NEW 18 Jun 2021) 
201 frequent in typically high montane genera such as Johnsonita, Rhamma, Podanotum, and 202 Penaincisalia (Table 1).

203

204

205

206

207

208

209

210

211

212

213

214

215

\section{Barcode gaps}

The percentage of species with a barcode gap in the complete data set was $87.2 \%$. However, the proportion of species from habitats at different elevations in the datasets affected barcode gap frequency. Gaps were observed in $95.7 \%$ of the species from lowland ecosystems $(0-1200 \mathrm{~m})$ while only $61.7 \%$ of species from exclusively high montane ecosystems ( $>2200 \mathrm{~m}$ ) had clear barcode gaps (Figures 2,3). The trend towards a higher percentage of barcode gaps in lowland species was also found when including genera with species distributed in both lowlands and midmontane habitats $(89.5 \%)$, exclusively mid montane habitats $(82.8 \%)$ and genera with exclusively mid- and high-montane species (73.8\%) (Table 2). The divergence values to the nearest neighbor were significantly lower in the high Andean species $(H=26.6, p$-value $=$ 0.0000002436 ), while the intra-specific divergence values were significantly lower in the lowland species $(H=6,49, p$-value $=0.01084)$.

216

\section{Discussion}

218

219

220

221

222

223

224

225

226

227

228

229

230

231

232

233

234

235

236

237

238

239

240

\section{BIN sharing}

In this study, we obtained 1839 sequences of 512 species distributed in 90 genera for $557 \mathrm{BIN}$ numbers, representing $78 \%$ of the available data on BOLD for the Eumaeini. From the set of specimens that yielded COI fragment lengths of at least $650 \mathrm{bp}, 75 \%$ of the a priori morphology-based identifications were unambiguously assigned to a single Barcode Index Number (BIN). After a taxonomic a posteriori review, the percentage of perfect matching rose to $85 \%$. Very low levels of interspecific barcode variation can reflect overlooked synonymy if misidentifications are ruled out (e.g Puillandre et al. 2011), but low genetic divergence, particularly based on just one genetic locus, does not automatically invalidate established taxonomy. In cases of recent phylogenetic divergence, phenotypic differentiation can occur more rapidly than the complete sorting of mtDNA into the new, separated lineages. The decision to consider two species names as synonyms must be made by a taxonomist. That is why in our study we strived for accurate identification before and after delimiting the species using molecular data. When species pairs with low barcode divergences are recovered as monophyletic groups in the cladograms or identification trees, and their morphology is highly divergent, they can be validated as two different species, particularly if both occur in sympatry. There is no fixed threshold level of divergence that indicates species status because the percentage of divergence that would indicate whether two entities belong to the same species depends on the taxonomic group being studied and its evolutionary history. Nevertheless, most studies have found that COI divergences rarely exceed $2 \%$ within named and morphologically validated species, while members of different species typically show higher divergences, and it has been shown repeatedly that this 'threshold' can be used in many or most metazoans to determine species 
241 status (Ratnasingham \& Hebert 2007, 2013). However, distance and geographic isolation are two 242 aspects that must be taken into account when delimiting biological entities based on established 243 thresholds. Two entities living in sympatry can be considered different species even when there 244 are small genetic divergences of $2 \%$ or less. But if these same entities are geographically distant, 245 a 2\% divergence may be considered irrelevant to define them as separate species.

246 The percentage of clearly different morphological species grouped within the same BIN was 247 predominantly high for the montane genus Rhamma, where the BIN BOLD:ABX0547 is shared

248 by five well-differentiated morphospecies, most of them flying in sympatry. We suggest that

249

250

251

252

253

254

255

256

257

258

259

260

261

262

263

264

265

266

267

268

269

270

271

272

273

274

275

276

277

278

279

280 most of the cases of BIN sharing between morphologically divergent high mountain species represent recently separated lineages that are still undergoing genetic differentiation. As most of these cases were recovered as monophyletic clades in the trees, a lower basic threshold setting in the algorithm would separate these species into different BIN numbers. However, it should be noted that with such modified settings and parameters the number of cases of BIN discordance in the same group of species may increase. In the case of the genus Rhamma the assignment of a single BIN number for clearly different morphological species is a result of the basic settings chosen for delimitation of sequences into BINs.

Incomplete lineage sorting is relatively common in recently and rapidly radiating species groups as these species often have not yet had the necessary time to fix alternative haplotypes or alleles (Galtier \& Daubin 2008). As a result, the relationships of incipient species typically progress from initial polyphyly through paraphyly and reach monophyly once lineage sorting is complete in the two sister species. Thus, in mtDNA analyses, relatively young species may appear polyphyletic or paraphyletic owing to incomplete lineage sorting (Tang et al. 2012). This phenomenon seems to be particularly common in high Andean genera such as Rhamma and has important effects on species identification and delimitation based on genetic sequence analysis. Further studies comparing genetic distances of sympatric and allopatric populations of several pairs of species can help to detect evidence of incomplete lineage sorting, and its prevalence in high mountain species of Theclinae.

\section{BIN splits}

High levels of intraspecific barcode variation often reflect cryptic species (e.g, Puillandre et al. 2011, 2012). However, deep barcode splits can also be the result of the recovery of pseudogenes, as a consequence of hybridization, or Wolbachia infection (Werren et al. 2008; Huemer et al. 2018, Mally et al. 2018). High percentages of BIN splits were found in some genera with typical mid- and high mountain representatives such as Podanotum, Johnsonita, Thaeides and Rhamma. As noted by Prieto et al. (2018), the genus Rhamma includes several species presenting both types of discordance, BIN sharing and BIN splitting (e.g., R. arria and R. bilix). Species with a wider geographical distribution in high Andean ecosystems, seem to show a greater number of incongruences. Morphologically identified specimens were placed in three well-differentiated BINs for $R$. arria (BOLD:ABX0547, BOLD:ADD3784, BOLD:ADD3785) and four BINs for $R$. bilix (BOLD:ACF3699, BOLD:ABX0491, BOLD:ADD1839, BOLD:ABX0493). These clades 
281

282

283

284

285

286

287

288

289

290

291

292

293

294

295

296

297

298

299

300

301

302

303

304

305

306

307

308

309

310

311

312

313

314

315

316

317

318

319

320

might correspond to either divergent conspecific lineages, or unconfirmed putative species separated, in some cases, by deep genetic divergences. Cases of mitochondrial introgression can hinder the delimitation of some Eumaeini species in the genus Calycopis (Cong et al. 2017), and we suppose that such processes occur more frequently in high Andean genera. Introgressive hybridization may have been common throughout the evolutionary history of these genera which are, therefore, of particular interest to taxonomists and evolutionary biologists because partial and unequal gene exchange can have important effects on the dynamics of speciation and phylogenetic patterns (Grant 1998; Grant et al. 2005; Funk and Omland 2003), and affect species identification and delimitation based on DNA sequences.

\section{Barcode gap analysis}

A useful display of distance data for species delimitation is a scatterplot showing for each species the maximum intraspecific variation against the minimum distance to the nearest nonconspecific species ('nearest neighbor'), with a 1:1 slope representing the point at which the difference between the two is zero (Collins \& Cruickshank 2013). This type of representation shows the barcode gap for each species in the dataset and can be an accurate display of the percentage of species in the study group that have a barcode gap (Figures 2,3). Since the identification of species and the delimitation of taxonomic entities using barcodes, depend on the existence of a clear DNA barcode gap, a quick visualization of the existence of these gaps in each species can indicate the usefulness of the DNA barcoding approach in a given genus. Major topographic and climatic variations are important factors that determine the nature of South American biodiversity. The geography of South America, together with its climate and biodiversity, have evolved over a very long period, initiated about $100 \mathrm{MY}$ ago on the ancient Gondwanan continent, although the Andes rose much later (about $25 \mathrm{MY}$ ago). Many species of butterflies are found near, or within, the complex valley systems of the Andes, a result of the combination of at least two important factors: altitudinal gradients and geographic barriers created by the intricate system of valleys and ridges (e.g. Holzinger \& Holzinger 1994; Willmott 2003; Ebel et al. 2015). The tectonic rise of the Andes has created new environments and modified others, and the uplift of the cordilleras has separated butterfly communities favoring the evolution of allopatric vicariants. Dramatic changes in global climate during glaciations, accompanied by major adjustments in vegetation, created new biomes which again may have stimulated the evolution of new species and subspecies, specially at high altitudes (Purser 2015; Pyrcz et al. 2017). These changes are quite rapid on a geological scale, and certain subspecies, notably among the high altitude pronophilines (Satyrinae), seem to have evolved since the last glacial maximum 20,000 years ago (Adams 1985; Pyrcz et al. 2009; Casner \& Pyrcz 2010). Several phylogenetic studies of butterflies indicate that the most recent diversification events tend to occur at high elevations and that the highest altitude species and subspecies are the youngest (e.g., Jiggins et al. 2006; Casner \& Pyrcz 2010; Pyrcz et al. 2017).

Due to incomplete lineage sorting in very young species, it is not easy to accurately define taxonomic boundaries, and additional difficulties may be caused by hybridization. Although the 
321

322

323

324

325

326

327

328

329

330

331

332

333

334

335

336

337

338

339

340

341

342

343

344

345

346

347

348

349

350

351

352

353

354

355

356

357

358

359

RESL algorithm as the basis for the BIN system (Ratnasingham \& Hebert 2013) provides a powerful tool to propose primary, tentative species hypotheses for large datasets (Ratnasingham and Hebert 2007), such an mtDNA-based approach cannot prove the absence of gene flow and still depends on arbitrary, a priori settings and assumptions. The efficiency of these methods largely depends on the accumulation of mtDNA mutations since species separation, and thus can only delimit lineages with sufficiently long isolation (Rannala 2015). Moreover, nothing is known about how the kind of speciation process (vicariance of an existing species versus a small founder colonization) might affect the ability of barcodes to identify species correctly. We assume that incomplete lineage sorting and occasional hybridization are usual phenomena in the very young species of South American Eumaeini, and that these are the two most likely causes of the low percentages of DNA barcode gaps found in high Andean species in comparison with the older species from the lowlands.

However, other very species-rich groups of Andean butterflies with recent speciation processes such as the subtribe Pronophilina, have shown very high percentages of barcode gaps and perfect congruence between morphology and DNA barcodes (e.g. Marín et al. 2017; Pyrcz et al. 2018). This shows that, in certain groups, other biological factors allow young high Andean species to present more complete DNA lineage sorting in short periods of time. In the case of Pronophilina, the low vagility of its species could be a determining factor that limits gene flow between separate populations and promotes lineage sorting.

\section{Conclusions}

In mtDNA analyses, relatively young species may appear polyphyletic or paraphyletic owing to incomplete lineage sorting, and other aspects such as introgressive hybridization may have been common throughout the evolutionary history of Eumaeini genera. Partial gene exchange can have important effects on the dynamics of speciation, and affect species delimitation based on DNA sequences. These phenomena seem to be particularly common in high Andean genera such as Rhamma and to have important effects on species identification based on genetic sequence analysis.

Since we found evidence, at least in the tribe Eumaeini, that relatively young species in young ecosystems tend to have more incongruences between morphology and DNA delimitation, and thus lower percentages of DNA barcode gaps, it would be interesting to find out if there are similar patterns when comparing groups of species belonging to related genera in young and old ecosystems at the same altitude. This could be done by comparing a group of high mountain species from the northern part of the Andes in Venezuela, with their relatives in the central part of the Andes in Peru. These two regions exhibit a different geological age of around $40 \mathrm{MY}$, with the Venezuelan part being the youngest.

\section{Acknowledgements}


360 For help and support in many ways we acknowledge Daniel Augusto Mantilla, (Popayán, 361 Colombia), Evgeny V. Zakharov (CCBD, Guelph, Canada), Pierre Boyer (France), Gregory 362 Nielsen, (Colombia), Myriam Nicolle Pertuz (Barranquilla, Colombia), Tomasz Pyrcz (Kracow, 363 Poland), Michael Balke (ZSM, Munich, Germany), Soranggy Cruzco (Barranquilla, Colombia) 364 and Zsolt Balint (HNHM, Budapest, Hungary).

365

366

367

368

369

370

371

372

373

374

375

376

377

378

379

380

381

382

383

384

385

386

387

388

389

390

391

392

\section{References}

Adams MJ 1985. Speciation in the Pronophiline Butterflies (Satyridae) of the Northern Andes. Journal of Research on the Lepidoptera, Supplement 1: 33-49.

Balint Zs, Faynel C. 2008. Review of the genus Brangas Hübner, 1819 (Lepidoptera:

Lycaenidae) with description of a new genus. Annales Historico-Naturales Musei Nationalis Hungarici, 100: 271-306.

Bergsten J, Bilton DT, Fujisawa T, Elliott M, Monaghan M, Balke M, Hendrich L, Geijer J, Herrmann J, Foster G, Ribera I, Nilsson A, Barraclough T, Vogles A. 2012. The effect of geographical scale of sampling on DNA barcoding. Systematic Biology, 61, 851-869.

Busby R, Faynel C, Moser A, Robbins RK. 2017. Sympatric diversification in the upper Amazon: A revision of the Eumaeine genus Paraspiculatus (Lepidoptera: Lycaenidae). Smithsonian Contributions to zoology, 649: 1-63.

Casner KL, Pyrcz TW. 2010. Patterns of timing of diversification in a tropical montane butterfly genus, Lymanopoda (Nymphalidae, Satyrinae). Ecography, 35: 1-9.

Collins RA, Cruickshank RH, 2013. The seven deadly sins of DNA barcoding. Molecular Ecology Resources, 6: 969-975.

Cong Q, Shen J, Borek D, Robbins RK, Otwinowski Z, Grishin NV. 2016. Complete genomes of Hairstreak butterflies, their speciation, and nucleomitochondrial incongruence. Scientific Reports, 6: 24863. (doi:10.1038/srep24863) 
393

394 Cong Q, Shen J, Borek D, Robbins RK, Opler PA, Otwinowski Z, Grishin NV. 2017. When COI

395 barcodes deceive: complete genomes reveal introgression in hairstreaks. Proceedings of the

396 Royal Society of London B, 284: 20161735.

397

398

deWaard JR, Ivanova NV, Hajibabaei M, Hebert PDN. 2008. Assembling DNA barcodes:

399

analytical protocols. In: C. Martin (Ed.), Methods in molecular biology: environmental genetics.

400

(pp. 275-293) Totowa: Humana Press Inc.

401

402

Dias FMS, Janzen D, Hallwachs W, Chacón I, Willmott K, Ortiz-Acevedo E, Mielke OHH, 403

Casagrande MM, 2019. DNA Barcodes uncover hidden taxonomic diversity behind the variable

404 wing patterns in the Neotropical butterfly genus Zaretis (Lepidoptera: Nymphalidae:

405

Charaxinae). Zoological Journal of the Linnean Society, 185 (1): 132-192.

406

407

Duarte M, Robbins RK. 2010. Description and phylogenetic analysis of the Calycopidina

408

(Lepidoptera, Lycaenidae, Theclinae, Eumaeini): a subtribe of detritivores, Revista Brasileira de

409

Entomologia, 54 (1): 45-65.

410

411 Ebel E, Da Costa JM, Sorenson M, Hill RI, Briscoe A, Willmott K, Mullen SP. 2015. Rapid

412 diversification associated with ecological specialization in Neotropical Adelpha butterflies.

413 Molecular Ecology, 24(10): 2392-2405.

414

415 Elias M, Hill R I, Willmott, KR, Mallet J, Jiggins CD. 2007. Limited performance of DNA 416 barcoding in a diverse community of tropical butterflies. Proceedings of the Royal Society of 417 London B, 274: 2881-2889.

418

419 Espinoza B, Janzen DH, Hallwachs W. 2017. 17 new species hiding in 10 long-named gaudy

420 tropical moths (Lepidoptera: Erebidae, Arctiinae). Tropical Lepidoptera Research, 27 (1): 1-29.

421

Peer] reviewing PDF | (2021:02:57879:2:0:NEW 18 Jun 2021) 
422 Faynel C. 2019. Le genre Chalybs Hübner, [1819] avec la description d'une nouvelle espéce du 423 plateau des Guyanes (Lepidoptera, Lycaenidae, Theclinae). Lambillionea, CXIX, 3, 424 (Supplément): 3-34.

425

426 Faynel C, Busby R, Moser A, Robbins RK. 2011. Species level taxonomy of the Neotropical 427 hairstreak genus Porthecla (Lepidoptera: Lycaenidae: Theclinae: Eumaeini). Annales de la 428 Société entomologique de France, 47 (1-2): 241-259.

429

430 Faynel C, Busby R, Robbins RK. 2012. Review of the species level taxonomy of the neotropical 431 butterfly genus Oenomaus (Lycaenidae, Theclinae, Eumaeini). ZooKeys, 222: 11-45. 432

433 Fujisawa T, Barraclough TG. 2013. Delimiting species using single-locus data and the 434 Generalized Mixed Yule Coalescent (GMYC) approach: a revised method and evaluation on 435 simulated datasets. Systematic Biology, 62: 707- 724.

436

437 Funk DJ, Omland KD. 2003. Species-level paraphyly and polyphyly: frequency, causes, and 438 consequences, with insights from animal mitochondrial DNA. Annual Review of Ecology, 439 Evolution, and Systematics, 34: 397-423.

440

441 Galtier N, Daubin V. 2008. Dealing with incongruence in phylogenomic analyses. Philosophical 442 Transactions of the Royal Society B-Biological Sciences, 363: 4023-4029.

443

444 Grant PR. 1998. Evolution on islands. Oxford (UK): Oxford University Press; p. 334. 445

446 Grant PR, Grant BR, Petren K. 2005. Hybridization in the recent past. American Naturalist, 166: $44756-67$.

449 Hajibabaei M, Janzen DH, Burns JM, Hallwachs W, Hebert PDN. 2006. DNA barcodes 450 distinguish species of tropical Lepidoptera. Proceedings of the National Academy of Sciences of 451 the United States of America, 103: 968-971. 
453 Hausmann A. 2011. An integrative taxonomic approach to resolving some difficult questions in 454 the Larentiinae of the Mediterranean region (Lepidoptera, Geometridae). Mitteilungen der 455 Münchner Entomologischen Gesellschaft, 101: 73-97.

456

457 Hausmann A, Haszprunar G, Segerer AH, Speidel W, Behounek G, Hebert PDN. 2011. Now 458 DNA-barcoded: The Butterflies and Larger Moths of Germany (Lepidoptera: Rhopalocera, 459 Macroheterocera). Spixiana, 34 (1): 47-58.

460

461 Hausmann A, Godfray HCJ, Huemer P, Mutanen M, Rougerie R, van Nieukerken EJ, 462 Ratnasingham S, Hebert PDN. 2013. Genetic Patterns in European Geometrid Moths Revealed 463 by the Barcode Index Number (BIN) System. PLoS ONE, 8 (12). doi:

464 10.1371/journal.pone.0084518.

465

466 Hawlitschek O, Morinière J, Lehmann GUC, Lehmann AW, Kropf M, Dunz A, Glaw F, 467 Detcharoen M, Schmidt S, Hausmann A, Szucsich NU, Caetano-Wyler SA, Haszprunar G. 2017. 468 DNA barcoding of crickets, katydids, and grasshoppers (Orthoptera) from Central Europe with 469 focus on Austria, Germany, and Switzerland. Molecular Ecology Resources, 17 (5). doi:

$470 \quad 10.1111 / 1755-0998.12638$

471

472 Hebert PDN, Cywinska A, Ball SL, DeWaard JR 2003. Biological identifications through DNA 473 barcodes. Proceedings of the Royal Society B: Biological Sciences, 270: 313-321. 474

Hebert PDN, Penton, EH, Burns JM, Janzen DH, Hallwachs W. 2004a. Ten species in one: DNA 476 barcoding reveals cryptic species in the neotropical skipper butterfly Astraptes fulgerator.

477 Proceedings of the National Academy of Sciences of USA, 101(41): 14812-14817.

478

Hebert PDN, Stoeckle MY, Zemlak TS, Francis CM. 2004b. Identification of birds through DNA 480 barcodes. PLoS Biology, 2:1657-1663.

481

482 Hebert PDN, deWaard JR, Landry JF. 2010. DNA barcodes for 1/1000 of the animal kingdom. 483 Biological Letters, 6: 359-362. doi:10.1098/rsbl.2009.0848. PubMed: 20015856. 
484

485 Holzinger H, Holzinger R. 1994. Heliconius and related genera. In: Heliconius and related 486 genera: Lepidoptera Nymphalidae; the genera Eueides, Neruda and Heliconius. Venette, France, 487 Sciences Nat. 328 pp., 51 pls.

488

489 Huemer P, Mutanen M, Sefc KM, Hebert PDN. 2014. Testing DNA Barcode Performance in 4901000 Species of European Lepidoptera: Large Geographic Distances Have Small Genetic 491 Impacts. PLoS ONE, 9(12): e115774. doi:10.1371/journal.pone.0115774.

492

493

Huemer P, Karsholt O, Aarvik L, Berggren K, Bidzilya O, Junnilainen J, Landry JFL, Mutanen

495

496

497

498

499

500

501

502

503

504

505

506

507

508

509

510

511 Jiggins CD, Mallarino R, Willmott KR, Bermingham E. 2006. The phylogenetic pattern of

512 speciation and wing pattern change in Neotropical Ithomia butterflies. Evolution, 60 (7): 1454 5131466.

514 barcode library for European Gelechiidae (Lepidoptera) suggests greatly underestimated species diversity. Zookeys, 921: 141-157. doi: 10.3897/zookeys.921.49199

Hendrich L, Morinière J, Haszprunar G, Hebert PDN, Hausmann A, Köhler F, Balke M. 2014. A comprehensive DNA barcode database for Central European beetles with a focus on Germany: adding more than 3500 identified species to BOLD. Molecular Ecology Resources, 15(4):795818 doi: $10.1111 / 1755-0998.12354$.

Ivanova NV, deWaard JR, Hebert PDN. 2006. An inexpensive, automation-friendly protocol for recovering high quality DNA. Molecular Ecology Notes, 6: 998-1002.

Janzen DH, Burns JM, Cong Q, Hallwachs W, Dapkey T, Manjunath R, Hajibabaei M, Hebert PDN, Grishin NV. 2017. Nuclear genomes distinguish cryptic species suggested by their DNA barcodes and ecology. Proceedings of the National Academy of Sciences of the United States of America, 114 (31): 8313-8318. doi:10.1073/pnas.1621504114.

M, Nupponen K, Segerer A, Šumpich J, Wieser Ch, Wiesmair B, Hebert PDN. 2018. DNA

PeerJ reviewing PDF | (2021:02:57879:2:0:NEW 18 Jun 2021) 
515 Kaila L, Stahls G. 2006. DNA barcodes: Evaluating the potential of COI to diffentiate closely 516 related species of Elachista (Lepidoptera: Gelechioidea: Elachistidae) from Australia. Zootaxa, 517 1170: 1-26.

518

519 Kerr KCR, Stoeckle MY, Dove CJ, Weigt LA, Francis CM, Hebert PDN. 2007. Comprehensive 520 DNA barcode coverage of North American birds. Molecular Ecology Notes, 7: 535-543.

521

522 Lavinia PD, Nuñez Bustos EO, Kopuchian C, Lijtmaer DA, García NC, Hebert PDN, Tubaro 523 PL. 2017. Barcoding the butterflies of southern South America: Species delimitation efficacy, 524 cryptic diversity and geographic patterns of divergence. PLOS ONE, 12(10): e0186845.

525 https://doi.org/ 10.1371/journal.pone.0186845

526

527 Mally R, Huemer P, Nuss M. 2018. Deep intraspecific DNA barcode splits and hybridisation in 528 the Udea alpinalis group (Insecta, Lepidoptera, Crambidae)-an integrative revision. ZooKeys, 529 746: 51-90. 10.3897/zookeys.746.22020

530

531 Marín MA, Cadavid IC, Valdés L, Álvarez CF, Uribe SI, Vila R, Pyrcz TW. 2017. DNA 532 barcoding of an assembly of montane Andean butterflies (Satyrinae): Geographical scale and 533 identification performance. Neotropical Entomology, 46: 514-523.

534

535 Morinière J, Balke M, Doczkal D, Geiger MF, Hardulak LA, Haszprunar G, Hausmann A, 536 Hendrich L, Regalado L, Rulik B, Schmidt S, Wägele JW, Hebert PDN. 2019. A DNA barcode 537 library for 5,200 German flies and midges (Insecta: Diptera) and its implications for 538 metabarcoding-based biomonitoring. Molecular Ecology Resources, 19: 900-928. 539

540 Ortiz A, Rubio R, Guerrero JJ, Garre MJ, Serrano J, Hebert PDN, Hausmann, A. 2017. Close 541 congruence between Barcode Index Numbers (BINs) and species boundaries in the Erebidae 542 (Lepidoptera: Noctuoidea) of the Iberian Peninsula. Biodiversity Data Journal, 5.e19840. DOI: 543 10.3897/BDJ.5.e19840. 
545 Pons J, Barraclough TG, Gomez-Zurita J, Cardoso A, Duran DP, Hazell S, Kamoun S, Sumlin

546 W, Vogler AP. 2006. Sequence based species delimitation for the DNA taxonomy of

547 undescribed insects. Systematic Biology, 55: 595-609.

548

549 Prieto C. 2011 The genus Micandra Staudinger (Lepidoptera: Lycaenidae: Theclinae) in 550 Colombia, with the description of a new species from the Sierra Nevada de Santa Marta, 551 Zootaxa, 3040: 55-68.

552

553 Prieto C, Bálint Zs, Boyer P, Micó E. 2008. A review of the "browni group" of Penaincisalia 554 with notes on their distribution and variability (Lepidoptera: Lycaenidae). Zootaxa, 1941: 1-24. 555

556 Prieto C, Micó E, Galante E. 2011. Molecules, Wing Pattern and distribution: an approach to 557 species delimitation in the "loxurina group" (Lepidoptera: Lycaenidae: Penaincisalia).

558 Neotropical Entomology, 40 (5): 553- 559.

559

560 Prieto C, Grishin N, Hausmann A, Lorenc-Brudecka J. 2016. The Penaincisalia amatista 561 species-group (Lepidoptera: Lycaenidae, Eumaeini) in Colombia, insights from mtDNA 562 barcodes and the description of a new species. Systematics and Biodiversity, 14 (2): 171-183. 563

564 Prieto C, Vargas MA. 2016. Elfin butterflies of the genus Rhamma Johnson (Lepidoptera:

565 Lycaenidae: Theclinae): A review of the Colombian species. Zootaxa, 4093 (3): 323-342.

566 https://doi.org/10.11646/zootaxa.4093.3.2

567

568 Prieto C, Lorenc-Brudecka J. 2017. Description of Rhamma dawkinsi (Lepidoptera: Lycaenidae) 569 a new mountain butterfly from Colombia. Zootaxa, 4338 (3): 587-594.

570

571 Prieto C, Nuñez R, Hausmann A. 2018. Molecular species delimitation in the genus Rhamma

572 Johnson, 1992 (Lepidoptera: Lycaenidae, Theclinae). Mitochondrial DNA, 30 (1): 1 -17. 573 
574 Puillandre N, Macpherson E, Lambourdiere J, Cruaud C, Boisselier MC, Samadi S. 2011.

575 Barcoding type specimens helps to identify synonyms and an unnamed new species in Eumunida 576 Smith, 1883(Decapoda: Eumunididae). Invertebrate Systematics, 25: 322-333.

577

578 Puillandre N, Lambert A, Brouillet S, Achaz G. 2012. ABGD, Automatic barcode gap discovery 579 for primary species delimitation. Molecular Ecology, 21(8): 1864-1877.

580 https://doi.org/10.1111/j.1365-294X.2011.05239.x

581

582

Purser B. 2015. Butterflies of the Andes: their biodynamics and diversification. The International 583 Biodiversity Foundation, Mariposa Press, Gainesville, Florida 251 pp.

584

585

Pyrcz T, Wojtusiak J, Garlacz R. 2009. Diversity and distribution patterns of Pronophilina 586 butterflies (Lepidoptera: Nymphalidae: Satyrinae) along an altitudinal transect in North-Western

587 Ecuador. Neotropical Entomology, 38(6):716-726.

588

589

590

Pyrcz, T, Lorenc-Brudecka J, Zubek A, Boyer P, Gabaldon C, Mavarez J. 2017. Taxonomy, 591 phylogeny and distribution of the genus Steromapedaliodes sensu novo in the Cordillera de Mérida, Venezuela (Lepidoptera: Nymphalidae: Satyrinae: Satyrini). Arthropod Systematics and 592 Phylogeny, 75(2): 195-243.

593

594 Pyrcz T, Prieto C, Boyer P, Lorenc-Brudecka J. 2018. Discovery of a remarkable new species of 595 Lymanopoda Westwood and considerations on its position in the generic phylogeny: an 596

597 integrative taxonomic approach (Lepidoptera, Nymphalidae, Satyrinae). European Journal of Entomology, 115: 387-399.

598

599 Tang QY, Liu SQ, Yu D, Liu HZ, Danley PD. 2012 Mitochondrial capture and incomplete 600 lineage sorting in the diversification of balitorine loaches (Cypriniformes, Balitoridae) revealed 601 by mitochondrial and nuclear genes. Zoologica Scripta, 41: 233-247.

602

603 Rannala B. 2015. The art and science of species delimitation. Current Zoology, 61: 846-853.

604 https://doi.org/10.1093/czoolo/61.5.846 
605

606 Ratnasingham S, Hebert PDN. 2007. BOLD: the barcode of life data system

607 (www.barcodinglife.org). Molecular Ecology Notes, 7: 355-364.

608

609 Ratnasingham S, Hebert PDN. 2013. A DNA-based registry for all animal species: The Barcode

610 Index Number (BIN) System. PLoS ONE, 8(8): e66213. doi:10.1371/journal.pone.0066213.

611

612 Riedel A, Sagata K, Surbakti S, Tänzler R, Balke M. 2013. One hundred and one new species of 613 Trigonopterus weevils from New Guinea. ZooKeys, 280.

614

615 Robbins RK. 2004. Lycaenidae. Theclinae. Tribe Eumaeini. In: Lamas G (Ed.) Checklist: Part 616 4A. Hesperioidea - Papilionoidea. In: Heppner JB (Ed.) Atlas of Neotropical Lepidoptera. 617 Volume 5A. Association for Tropical Lepidoptera and Scientific Publishers, Gainesville, FL, $618118-137$.

619

620 Robbins RK, Heredia AD, Busby RC. 2015. Male secondary sexual structures and the 621 systematics of the Thereus oppia species group (Lepidoptera, Lycaenidae, Eumaeini). ZooKeys, 622 520: 109-130.

623

624 Rougerie R, Kitching IJ, Haxaire J, Miller SE, Hausmann A, Hebert PDN. 2014. Australian 625 Sphingidae - DNA barcodes challenge current species boundaries and distributions. PLoS ONE, 626 9(7): e101108. doi:10.1371/journal.pone.0101108

627

628 Schmidt S, Schmid-Egger C, Moriniere J, Haszprunar G, Hebert P. 2015. DNA barcoding 629 largely supports 250 years of classical taxonomy: Identifications for Central European bees 630 (Hymenoptera, Apoidea partim). Molecular Ecology Resources, 15. 10.1111/1755-0998.12363. 631

632 Shapiro SS, \& Wilk, MB. 1965. An analysis of variance test for normality (complete samples). 633 Biometrika, 52(3-4), 591-611. https://doi.org/10.1093/biomet/52.3-4.591 634 
635 Smith MA, Woodley NE, Janzen DH, Hallwachs W, Hebert PDN. 2006. DNA barcodes reveal 636 cryptic host-specificity within the presumed polyphagous members of a genus of parasitoid flies 637 (Diptera: Tachinidae). Proceedings of the National Academy of Sciences of USA, 103: 36576383662.

639

640 Tujuba TF, Hausmann A, Sciarretta A. 2020. Revision of the Orbamia Herbulot, 1966 group of 641 genera with description of two new genera, ten new species, and two new subspecies

642 (Lepidoptera, Geometridae, Ennominae, Cassymini). ZooKeys, 929: 53-77.

643 https://doi.org/10.3897/zookeys.929.50391.

644

645 vanVelzen R, Bakker FT, vanLoon JJA. 2007. DNA barcoding reveals hidden species diversity 646 in Cymothoe (Nymphalidae). Proceedings of the Netherlands Entomological Society Meeting, 647 18: 95-103.

648

649 Werren JH, Baldo L, Clark ME. 2008. Wolbachia: master manipulators of invertebrate biology. 650 Nature Reviews Microbiology, 6: 741-751.

651

652 Willmott, K. 2003. The genus Adelpha: its systematics, biology and biogeography (Lepidoptera: 653 Nymphalidae: Limenitidini). Gainesville, FL, Scientific Publishers, 322pp.

654

655 Wirta H, Várkonyi G, Rasmussen C, Kaartinen R, Schmidt NM, Hebert PDN, Barták M, 656 Blagoev G, Disney H, Ertl S, Gjelstrup P, Gwiazdowicz DJ, Huldén L, Ilmonen J, Jakovlev J, 657 Jaschhof M, Kahanpää J, Kankaanpää T, Krogh PH, Labbee R, Lettner C, Michelsen V, Nielsen 658 SA, Nielsen TR, Paasivirta L, Pedersen S, Pohjoismäki J, Salmela J, Vilkamaa P, Väre H, 659 Tschirnhaus Mv, Roslin T. 2015. Establishing a community-wide DNA barcode library as a new 660 tool for arctic research. Molecular Ecology Resources, 16 (3): 809-822.

661 https://doi.org/10.1111/1755-0998.12489. 
Figure 1

Map of South America

Distribution of sequenced material of Eumaeini (Lycaenidae, Theclinae).

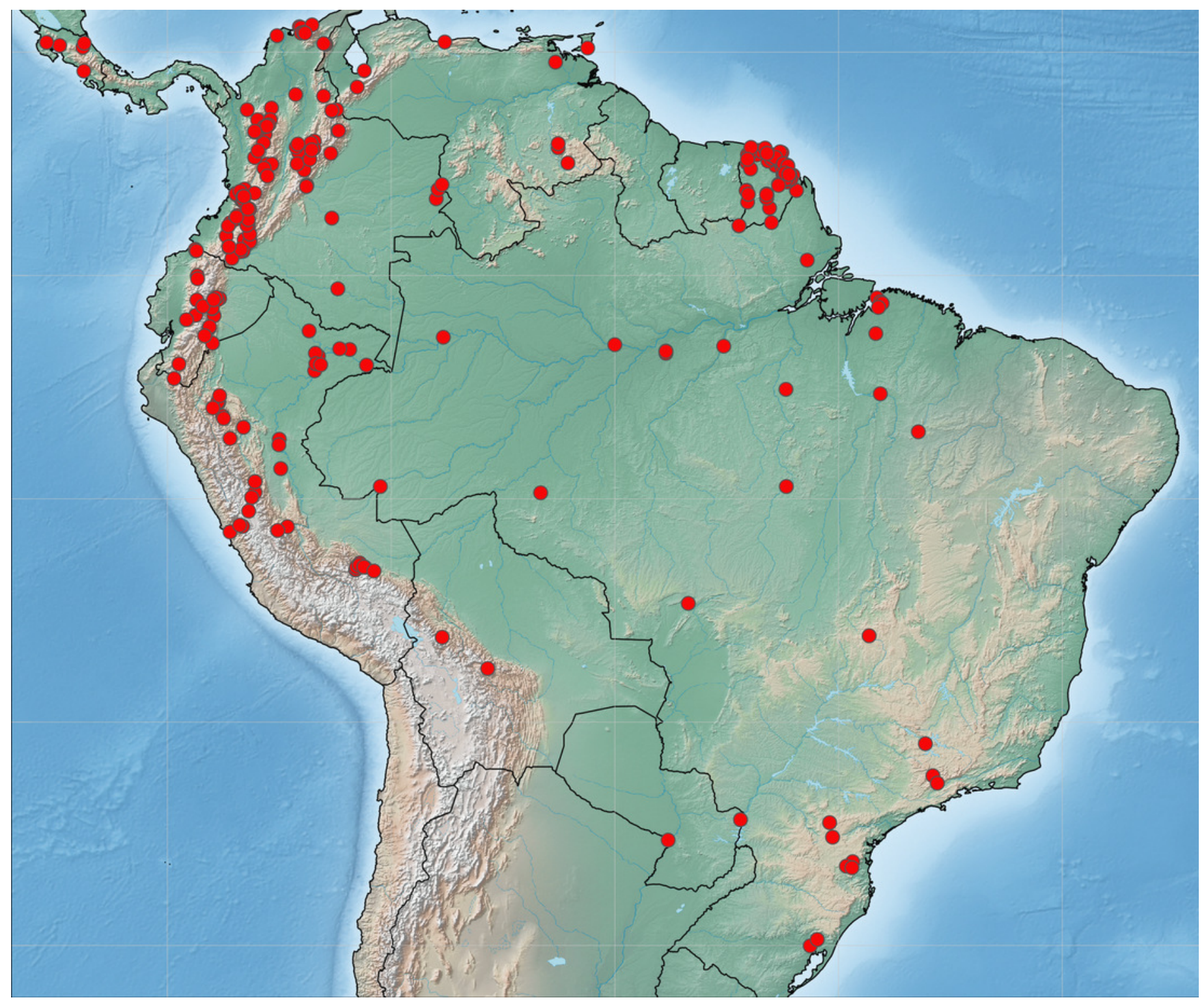




\section{Figure 2}

Distance data for the barcode gap analysis

Scatterplots are provided to confirm the existence and magnitude of barcode gaps for the complete set of species and for groups of genera including mid + high mountain and lowland + mid-mountain species. The first two scatterplots show the overlap of the max and mean intraspecific distances vs the interspecific (nearest neighbour) distances. In the three groups of altitude most species fall above the 1:1 line, indicating the presence of a barcode gap (for percentages see Table 2). The third scatterplot plots the number of individuals in each species against their max intraspecific distances, as a test for sampling bias. 

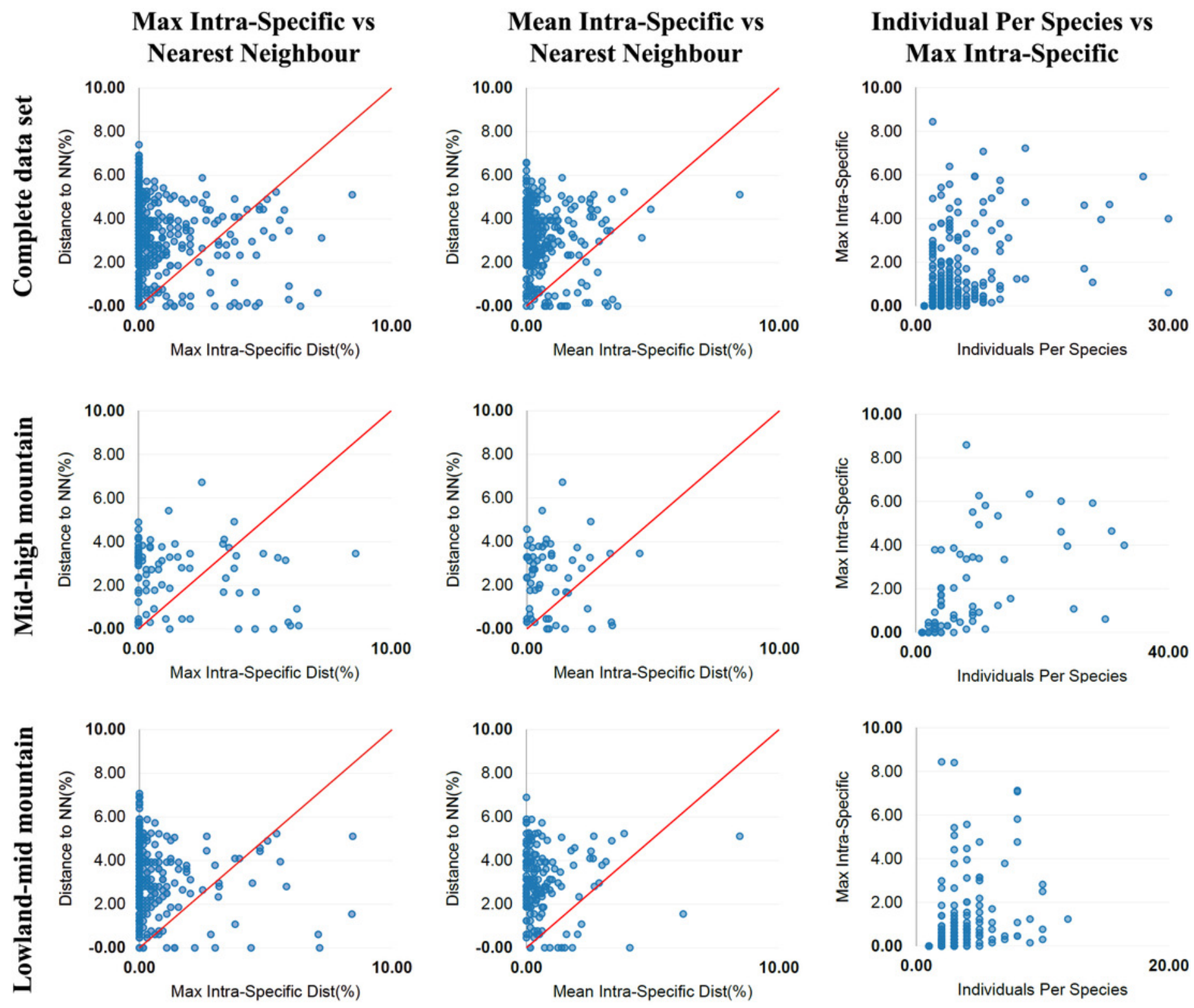


\section{Figure 3}

Distance data for the barcode gap analysis.

Scatterplots are provided to confirm the existence and magnitude of barcode gaps for exclusively high mountain genera, mid-mountain genera and lowland genera. The first two scatterplots show the overlap of the max and mean intraspecific distances vs the interspecific (nearest neighbor) distances. Lowland genera show a higher percentage of species with local barcode gaps (points above the 1:1 line) than mid and high mountain genera (see Table 2). The third scatterplot plots the number of individuals in each species against their max intraspecific distances, as a test for sampling bias. 

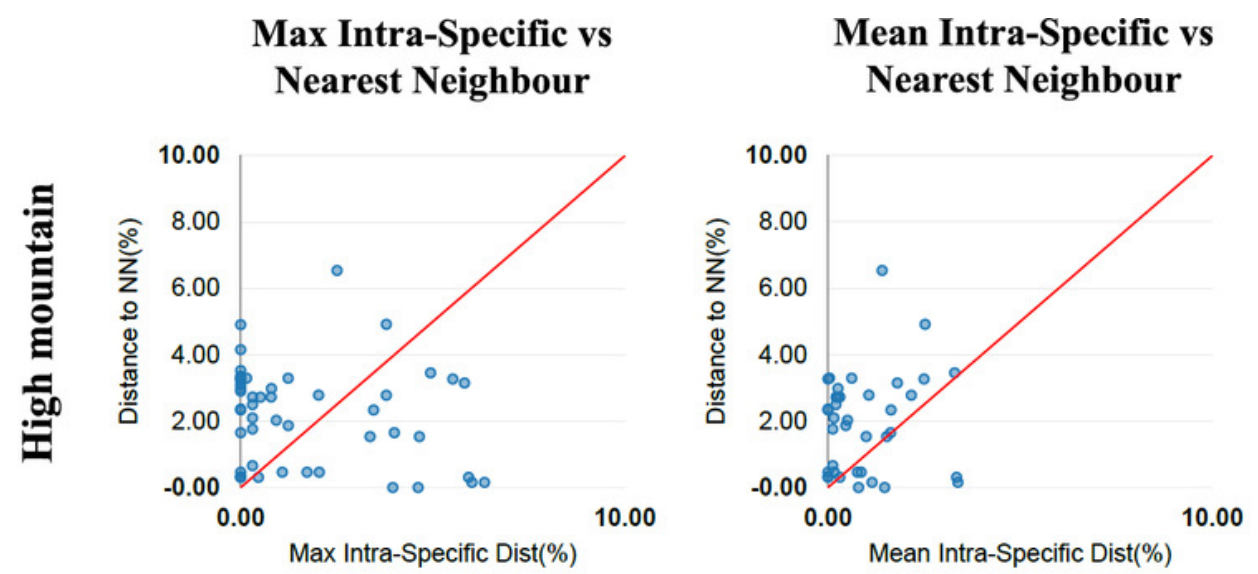

\section{Individuals per Species vs Max Intra-Specific}
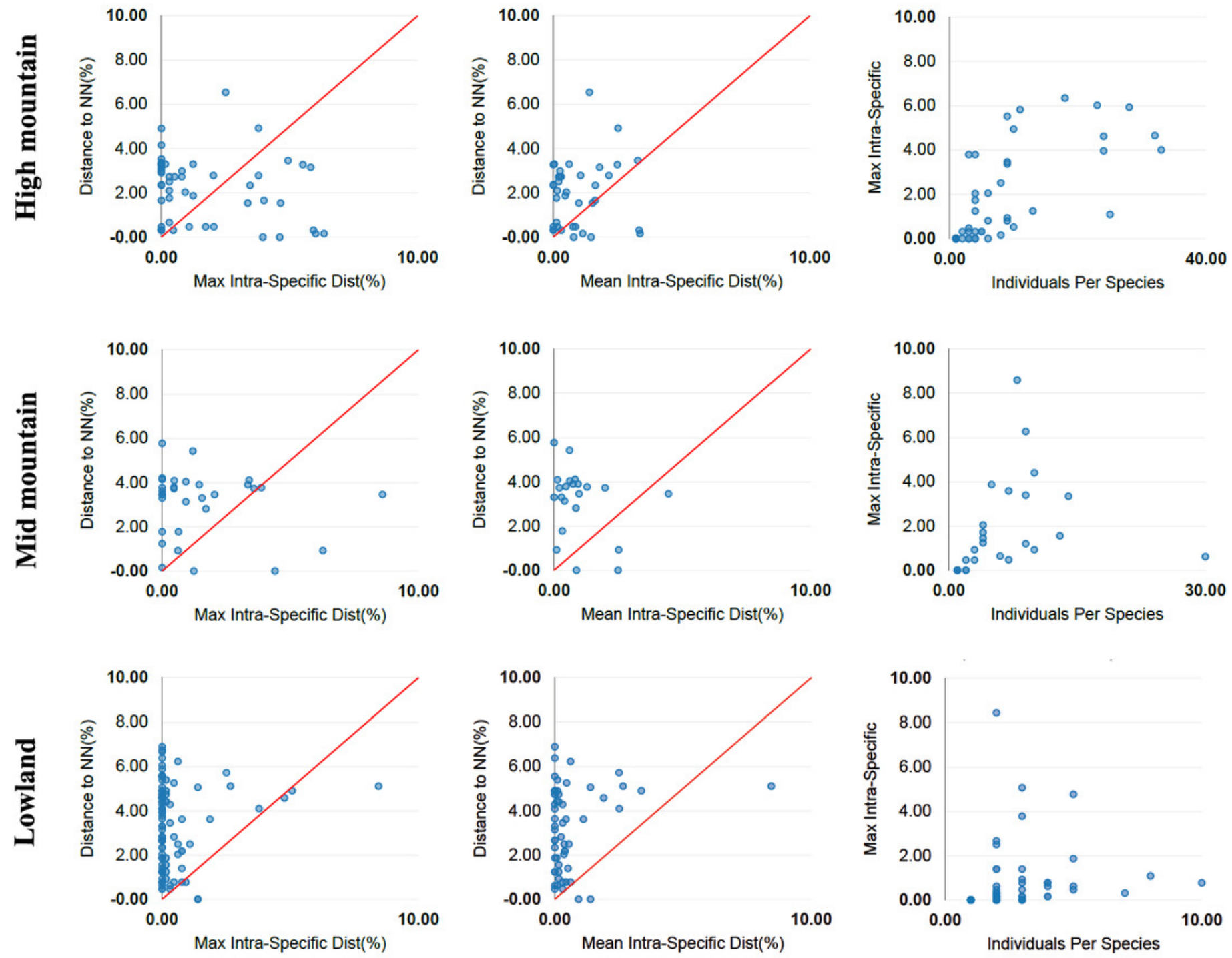


\section{Table $\mathbf{1}$ (on next page)}

Summary of the percentages of congruence between BIN's and morphology-based identifications.

Analysis for 52 genera of Eumaeini (Lycaenidae, Theclinae) represented by perfect matches, BIN splitting, and BIN sharing. Percentages were corrected (number in parentheses) when the BIN clustering indicated to the taxonomist a confirmed synonymy or cryptic species, in both cases we assume that the BIN designation was correct and the a priori morphological identification was wrong. Maximum intraspecific distance and minimum interspecific distances are highlighted when a clear barcode gap exists. Some species can present BIN sharing and BIN splitting at the same time, which makes the sum of the percentages of perfect match, BIN sharing and BIN splitting exceed $100 \%$ for the genus. 


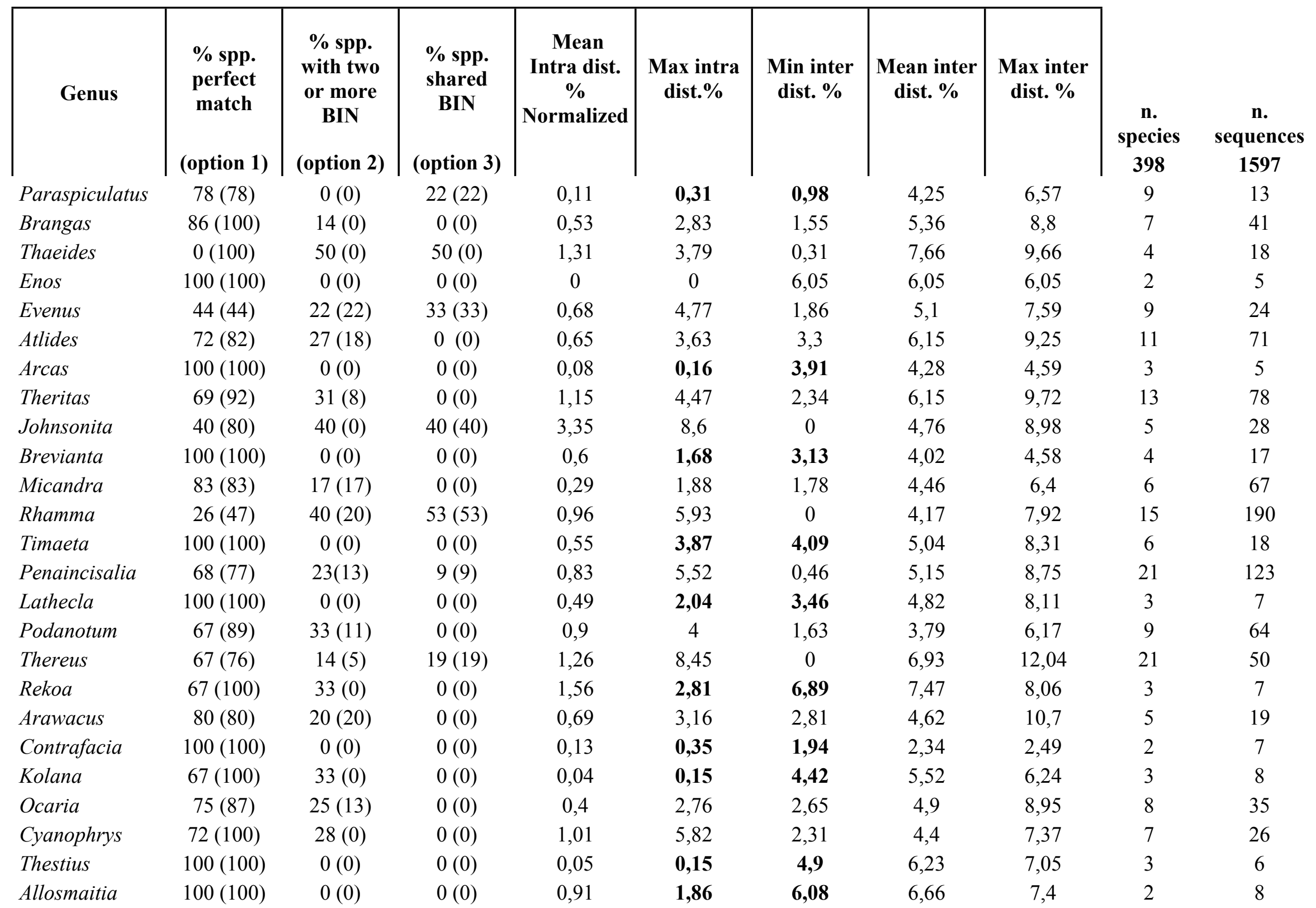




\begin{tabular}{|c|c|c|c|c|c|c|c|c|c|c|}
\hline Janthecla & $60(60)$ & $0(0)$ & $40(0)$ & 0,32 & 0,93 & 0,77 & 6,49 & 9,74 & 5 & 10 \\
\hline Lamprospilus & $83(92)$ & $17(8)$ & $0(0)$ & 0,73 & 4,79 & 3,46 & 5,8 & 8,49 & 12 & 51 \\
\hline Arzecla & $75(100)$ & $25(0)$ & $0(0)$ & 0,05 & 0,31 & 3,78 & 6,78 & 8,06 & 8 & 43 \\
\hline Arumecla & $100(100)$ & $0(0)$ & $0(0)$ & 0,04 & 0,16 & 5,91 & 6,66 & 7,78 & 5 & 11 \\
\hline Electrostrymon & $80(100)$ & $20(0)$ & $0(0)$ & 0,68 & 2,89 & 1,55 & 6,02 & 7,16 & 5 & 22 \\
\hline Strymon & $94(94)$ & $6(6)$ & $0(0)$ & 0,41 & 3,09 & 2,67 & 8,11 & 12,21 & 17 & 27 \\
\hline Tmolus & $60(100)$ & $40(0)$ & $0(0)$ & 0,44 & 0,93 & 2,65 & 4,59 & 8,63 & 5 & 12 \\
\hline Nicolaea & $100(100)$ & $0(0)$ & $0(0)$ & 0,3 & 1,08 & 2,18 & 7,07 & 10,56 & 11 & 18 \\
\hline Ministrymon & $83(83)$ & $17(17)$ & $0(0)$ & 1,01 & 2,82 & 1,55 & 5,32 & 7,06 & 6 & 11 \\
\hline Gargina & $75(75)$ & $25(25)$ & $0(0)$ & 0,75 & 8,96 & 4,27 & 7,75 & 10,01 & 4 & 21 \\
\hline Siderus & $71(100)$ & $29(0)$ & $0(0)$ & 2,24 & 5,83 & 0 & 7,4 & 10,9 & 7 & 20 \\
\hline Theclopsis & $75(75)$ & $25(25)$ & $0(0)$ & 1,41 & 2,51 & 4,41 & 6,12 & 7,62 & 4 & 7 \\
\hline Ostrinotes & $100(100)$ & $0(0)$ & $0(0)$ & 0,26 & 0,82 & 2,2 & 6,2 & 8,42 & 7 & 13 \\
\hline Strephonota & $65(77)$ & $27(15)$ & $11(11)$ & 0,85 & 7,99 & 0 & 4,82 & 10,39 & 26 & 103 \\
\hline Panthiades & $88(88)$ & $12(12)$ & $0(0)$ & 0,76 & 3,34 & 1,87 & 4,53 & 6,55 & 8 & 20 \\
\hline Oenomaus & $61(61)$ & $26(26)$ & $26(26)$ & 1,17 & 7,63 & 0 & 5,91 & 9,9 & 23 & 86 \\
\hline Porthecla & $100(100)$ & $0(0)$ & $0(0)$ & 0,49 & 1,55 & 3,45 & 5,59 & 7,26 & 5 & 13 \\
\hline Thepytus & $67(67)$ & $33(33)$ & $0(0)$ & 0,61 & 2,02 & 4,73 & 5,81 & 7,61 & 3 & 8 \\
\hline Parrahasius & $100(100)$ & $0(0)$ & $0(0)$ & 0,07 & $\mathbf{0 , 3 1}$ & 2,6 & 3,21 & 3,77 & 3 & 7 \\
\hline Michaelus & $100(100)$ & $0(0)$ & $0(0)$ & 0,08 & 0,15 & 4,41 & 4,99 & 5,43 & 4 & 7 \\
\hline Ignata & $100(100)$ & $0(0)$ & $0(0)$ & 0,19 & 0,86 & 2,05 & 4,27 & 7 & 5 & 9 \\
\hline Olynthus & $71(71)$ & $0(0)$ & $29(29)$ & 0,2 & 0,81 & 0,65 & 2,67 & 4,57 & 14 & 36 \\
\hline Marachina & $100(100)$ & $0(0)$ & $0(0)$ & 0,31 & 0,93 & 5,88 & 6,05 & 6,22 & 2 & 5 \\
\hline Aubergina & $100(100)$ & $0(0)$ & $0(0)$ & 0,17 & 0,32 & 9,99 & 10,36 & 10,68 & 2 & 13 \\
\hline Iaspis & $100(100)$ & $0(0)$ & $0(0)$ & 0,32 & 1,44 & 2,58 & 4,56 & 6,23 & 5 & 9 \\
\hline Erora & $92(100)$ & $8(0)$ & $0(0)$ & 1,3 & 4,92 & 2,02 & 6,06 & 8,9 & 12 & 23 \\
\hline Chalybs & $89(100)$ & $11(0)$ & $0(0)$ & 0,22 & 1,17 & 0,34 & 5,89 & 8,76 & 9 & 57 \\
\hline
\end{tabular}




\section{Table 2 (on next page)}

Percentages of congruence and barcode gaps.

Percentage of species with barcode gap and percentage of species with perfect congruence between BINs and morphospecies for each group of genera depending on altitude.

Exclusively lowland genera present a higher percentage of species with barcode gaps than exclusively high mountain and mid-mountain species. 


complete set
mid-mountain + high mountain
lowland + mid-mountain
high mountain
mid-mountain
lowland

1

\section{Individuals}

\section{Genera}

1834

741

1078

482

259

339

\section{Species}

485

84

244

47

35

118
BINs

556

112

261

67

45

114
\% spp with perfect congruence BIN vs morphology

$$
84.6
$$

79.1

86.0

71.4

82.2

85.2 